\title{
A GENÉTICA EM SALA DE AULA: UMA ANÁLISE DAS PERCEPÇÕES E METODOLOGIAS EMPREGADAS POR PROFESSORES DAS ESCOLAS PÚBLICAS ESTADUAIS DE JAGUARIBE CEARÁ
}

\author{
EdJÉSSiCA Siqueira de SOUSA ${ }^{1}$, Francisco Holanda NunEs Junior ${ }^{1}$, \\ Cícero Antonio Maia Cavalcante ${ }^{1}$, Denise de Araújo Silva Holanda ${ }^{2}$ \\ Instituto Federal do Ceará, ${ }^{1}$ Campus de Jaguaribe, ${ }^{2}$ Campus de Cedro \\ <edjessicasiqueira@gmail.com>, <holandajrb@gmail.com> \\ <cicero.carla@uol.com.br>.<denise.sholanda@gmail.com> \\ DOI: $10.21439 /$ conexoes.v10i4.1106
}

\begin{abstract}
Resumo. O conteúdo de genética tem enfrentado uma série de dificuldades em ser compreendido pelos alunos em várias escolas desse país. Muitas delas são atribuídas a deficiências em conhecimentos prévios da área da Biologia Molecular, Citologia e, principalmente, ao raciocínio matemático. Além disso, as ferramentas metodológicas, empregadas por muitos dos professores, não têm contribuído para uma aprendizagem significativa do tema. Dessa forma, o presente trabalho buscou identificar as percepções e principais metodologias empregadas pelos professores da disciplina de Biologia no conteúdo de genética das escolas estaduais, localizadas no município de Jaguaribe-CE, analisando a percepção desses profissionais e dos alunos acerca do ensino - aprendizagem do conteúdo ministrado nas aulas. A pesquisa bibliográfica e de campo foi realizada nos meses de Junho e Julho de 2015. Além disso, foram aplicados questionários semiestruturados em um total de 06 professores e 54 alunos, versando sobre as metodologias empregadas no ensino de Genética, bem como a percepção deles em relação à influência dos procedimentos metodológicos na aprendizagem do conteúdo. Diante dos resultados encontrados na pesquisa, foi possível perceber que o ensino de genética nas escolas estaduais de Jaguaribe ainda está voltado, principalmente, para modelos tradicionais, com a prevalência de métodos expositivos de explicação do conteúdo. De maneira adicional, percebeu-se que os alunos possuem dificuldade em compreender o conteúdo de genética, devido a déficits de formação de base em outras disciplinas, principalmente a Matemática, que é bastante utilizada dentro dos cruzamentos e nos cálculos de probabilidade.
\end{abstract}

Palavras-chaves: Ensino Médio. Ensino de Genética. Metodologias.

\begin{abstract}
The genetic content has faced a number of difficulties in being understood by students in various schools of the country. Many of them are attributed to deficiencies in prior knowledge of the area of Molecular Biology, Cytology and mainly to mathematical reasoning. Moreover, the methodological tools employed by many of the teachers have not contributed to a significant learning theme. Thus, this study sought to identify main perceptions and methods used by the Biology discipline teacher in content genetics of state schools located in the city of Jaguaribe-CE, analyzing the perception of these professionals and students about the teaching - learning of the content taught in class. The literature and field research was conducted in June and July 2015. In addition, semi-structured questionnaires for a total of 06 teachers and 54 students were applied, dealing with the methodologies employed in genetics education, as well as their perception regarding the influence of methodological procedures in content learning. Given the results found in the survey, it was revealed that the genetic teaching in state schools of Jaguaribe is still geared primarily to traditional models, with the prevalence of expository methods of content explanation. Additional way, it was noticed that students have difficulty understanding the genetic content, due to basic training deficits in other subjects, especially mathematics, which is widely used within the intersections and probability calculations.
\end{abstract}

Keywords: High School. Genetics Education. Methodologies. 


\section{INTRODUÇÃO}

A genética é a ciência que estuda a hereditariedade através dos genes, variação, transmissão e expressão das informações genéticas nos seres vivos (KLUG et al. 2010). A ciência se desenvolveu durante o século $\mathrm{XX}$, tendo sua origem nos trabalhos realizados pelo monge austríaco Gregor Mendel (SNUSTAD; SIMMONS, 2012). Nos seus experimentos, Mendel estudou a herança de diferentes características em ervilhas, sendo sua pesquisa bastante relevante para os dias atuais (FLORIA-SANTOS; NASCIMENTO, 2006).

Durante muito tempo, os conhecimentos genéticos tiveram sua aplicação voltada, principalmente, para o melhoramento e seleção de linhagens mais produtivas de plantas e animais para o consumo humano (ALBANO, 2000). O direcionamento para pesquisas dentro das áreas médicas deu-se mais recentemente com o desenvolvimento do projeto Genoma Humano e os possíveis avanços na busca pela cura de doenças (ZATZ 2000).

Segundo Sardinha, Fonseca e Goldbach (2009), o ensino da genética nas escolas possui grande importância na alfabetização científica. No entanto, as maiores dificuldades relatadas por alunos e professores relacionam-se, principalmente, a complexidade no vocabulário da disciplina, o que tem acarretado incompreensão do conhecimento historicamente acumulado.

Dessa forma, é necessária a utilização de ferramentas metodológicas que propiciem um ensino mais adequado e que seja capaz de chamar a atenção dos alunos para uma participação ativa na construção do saber (WEINGARTNER, 2014).

Nas escolas brasileiras, a temática normalmente é abordada no $3^{\circ}$ ano do Ensino Médio, na disciplina de Biologia. Por exigir dos alunos conhecimentos prévios em diferentes áreas, como: Biologia Molecular, Citologia, Citogenética e raciocínio matemático, o conteúdo normalmente é visto como sendo de difícil entendimento (MOREIRA; SILVA, 2001, CANAL; BASTOS 2001).

Lima et al. (2006), corroboram com tal premissa e enfatizam as influências negativas que uma frágil formação em conteúdos anteriores pode ocasionar no entendimento da genética. Segundo costa (2000), somente uma relação adequada entre os conhecimentos prévios e os novos conteúdos são capazes de possibilitar ao aluno reconhecer melhor as relações de transmissão das características hereditárias, propostas pelo conteúdo de genética.

Os Parâmetros Curriculares Nacionais para o Ensino Médio (BRASIL, 1999), destacam a importância de se promover um ensino voltado para a apropriação do conhecimento pelos educandos, tornando-os capazes de relacionar o conteúdo ao seu cotidiano. Para facilitar essa associação, o documento subdivide a temática em quatro unidades (Os fundamentos da hereditariedade; Genética humana e saúde; Aplicações da engenharia genética; Os benefícios e os perigos da manipulação genética: um debate ético) tornando o conhecimento significativo e útil para os estudantes, independentemente de suas particularidades.

O desenvolvimento de habilidades e competências no ensino de Biologia deve ter como meta proporcionar conhecimento aos alunos, estimulando a apropriação crítica do conteúdo. Dessa forma, Franzolin e Bizzo (2013) afirmam que dentre os saberes produzidos pela Biologia, os conhecimentos em genética apresentam grande relevância, seja por sua importância para várias áreas das Ciências biológicas, seja por sua conexão em diversos aspectos do cotidiano dos indivíduos.

Dessa forma, é essencial que todos os educadores tenham um conhecimento amplo na disciplina de genética, a fim de demonstrar e aproximar o conhecimento teórico do cotidiano do educando, além de possibilitar uma melhor compreensão da disciplina. Assim, como preconiza BRASIL (1999), deve-se "difundir os princípios da reforma curricular do Ensino Médio e orientar o professor, na busca de novas abordagens e metodologias" (BRASIL, 1999).

Nesse contexto, o presente trabalho buscou identificar as principais metodologias empregadas pelos professores da disciplina de genética, das escolas estaduais localizadas no município de Jaguaribe-CE, analisando a percepção dos professores e dos alunos acerca da aprendizagem do conteúdo. Além de relacionar tais percepções aos problemas verificados na aprendizagem do conteúdo de genética, e suscitar possíveis alternativas que facilitem o processo ensino-aprendizagem.

\section{METODOLOGIA}

A pesquisa, do tipo quali-quantitativa, teve como público-alvo professores de genética e alunos do Ensino Médio das escolas públicas estaduais do município de Jaguaribe, Ceará, Brasil. Foram feitas análises bibliográficas e de campo, levando em consideração as metodologias empregadas pelos professores de biologia que ministravam a genética, analisando a percepção dos professores e dos alunos acerca da aprendizagem do conteúdo.

Na pesquisa bibliográfica, adota-se referenciais teóricos relacionados à temática, com o intuito de se entender o contexto do ensino da Biologia e, consequentemente, da genética. 
A GENÉTICA EM SALA DE AULA: UMA ANÁLISE DAS PERCEPÇÕES E METODOLOGIAS EMPREGADAS POR PROFESSORES DAS ESCOLAS PÚBLICAS ESTADUAIS DE JAGUARIBE CEARÁ

Posteriormente, iniciou-se a pesquisa de campo realizada no período de Junho e Julho de 2015, possibilitando a obtenção de dados sobre o desenvolvimento de metodologias utilizadas por professores no ensino de genética, bem como suas percepções acerca da temática em questão.

A amostra da pesquisa foi composta por 06 professores e 54 alunos dos terceiros anos do Ensino Médio das escolas: Escola de Ensino Médio Cornélio Diógenes; Escola de Ensino Médio Raul Barbosa e Escola Estadual de Educação Profissional Poeta Sinó Pinheiro, localizadas na zona urbana da cidade de Jaguaribe, e Escola de Ensino Médio Gustavo Barroso e Escola de Ensino Médio Militana Paes, ambas localizadas nos distritos de Nova Floresta e Feiticeiro, respectivamente, na zona rural do município.

Priorizou-se, como instrumento para coleta de dados dessa amostra, questionários semiestruturados, aplicados a professores e alunos, versando sobre as metodologias empregadas no ensino de Genética, bem como acerca da percepção deles em relação à influência de tais metodologias na aprendizagem do conteúdo.

Quanto aos critérios de seleção dos entrevistados, todos os professores dos terceiros anos do Ensino Médio lotados pela Secretaria de Educação do Estado do Ceará na sua representatividade local da $11^{\mathrm{a}}$ Coordenadoria Regional de Desenvolvimento da EducaçãoCREDE e os alunos regulamente matriculados nos terceiros anos do Ensino Médio que tiveram aulas do conteúdo de genética foram selecionados.

Vale salientar que as perguntas eram, em sua maioria, de natureza objetiva. O procedimento foi realizado com autorização de todos os envolvidos na pesquisa, mantendo-se o anonimato durante as entrevistas ao longo do estudo, como também, foram respeitadas as condições éticas e técnicas, utilizando o Termo de Consentimento Livre e Esclarecido.

No que diz respeito à análise dos dados, estes foram coletados, agrupados em respostas similares, apresentados em gráficos e tabelas de porcentagem relativa e discutidos conforme proposta de avaliação qualitativa de Bardini (2009), com base nos objetivos propostos no estudo.

\section{RESULTADOS E DISCUSSÕES}

\subsection{Perfil dos docentes entrevistados}

De acordo com os dados obtidos, através da aplicação dos questionários, os professores que lecionam o conteúdo de genética das escolas estaduais do município de Jaguaribe apresentam média de idade de 35 anos. Todos afirmaram possuir experiência no ensino da matéria de
Biologia, sendo que $50 \%$ do total atuam no magistério por, pelo menos, 10 anos.

Ao analisarmos a formação desses profissionais, verificou-se que $100 \%$ apresentam nível superior, distribuídos de acordo com a Tabela 1 .

Tabela 1: Lista de dissertações selecionadas.

\begin{tabular}{c|cc}
\hline \hline Curso & $\mathrm{N}^{o}$ & $\%$ \\
\hline Licenciatura em Ciências Biológicas & 3 & 50 \\
Licenciatura em Química e Biologia & 3 & 50 \\
\hline Total & 6 & 100 \\
\hline \hline
\end{tabular}

Em relação ao nível formação, percebe-se que todos os entrevistados apresentam licenciatura, tal como preconiza a lei de Diretrizes e Bases da Educação Brasileira - LDB (lei 9394/96), em seu Art. 62, que para o exercício do magistério, na educação básica, o docente precisará de curso superior e de licenciatura em universidades e institutos superiores de educação.

Fica claro que as escolas estaduais, do município de Jaguaribe, estão em conformidade com o que preconiza a legislação supracitada. Segundo

Galiazzi e Goncalves (2004), para um professor, é de fundamental importância possuir licenciatura, pois necessita possuir conhecimentos objetivos, ressaltado a importância da ação pedagógica na formação profissional de seus alunos.

Com referência à carga horária semanal dos professores e sua distribuição em uma ou mais escolas, constatou-se que estes profissionais trabalham, em média, 33 horas/semanais, contabilizados nesse total cerca de 10 horas, destinadas ao planejamento. A maioria deles $(67 \%)$ desenvolve essa carga horária em apenas uma instituição de ensino.

Verificou-se no estudo que o tempo destinado a planejamento, encontra-se próxima de $1 / 3$ (um terço) da média de carga horária, estando de acordo com o estabelecido na Lei Federal 11.738/2008, que regula o piso salarial nacional dos profissionais do magistério público da Educação Básica. A referida Lei determina que os educadores, da educação básica, devem possuir, no máximo, 40 (quarenta) horas semanais com valor do piso salarial profissional nacional e especifica o limite máximo de 2/3 (dois terços) da carga horária para o desempenho das atividades de interação com alunos. Desta forma, no mínimo, 1/3 da jornada de trabalho devem ser destinadas às chamadas atividades extraclasses.

Adicionalmente, pode-se inferir que, apesar da maioria dos professores trabalharem em uma única escola, ainda torna-se representativo o total de entrevistados, 
A GENÉTICA EM SALA DE AULA: UMA ANÁLISE DAS PERCEPÇÕES E METODOLOGIAS EMPREGADAS POR PROFESSORES DAS ESCOLAS PÚBLICAS ESTADUAIS DE JAGUARIBE CEARÁ

(33\%), que atuam em mais de uma unidade educacional, o que possivelmente poderia refletir indiretamente na qualidade do ensino. Segundo Gouveia et al. (2006), as duplas jornadas, enfrentadas por muitos professores, dificultam a busca por atualização profissional, além de refletirem de forma significativa na exaustão física e surgimento de problemas de saúde, o que consequentemente reduziria a capacidade laboral do profissional.

\subsection{Perfil dos docentes entrevistados}

Inicialmente verificou-se o grau de afinidade dos professores de Biologia com o conteúdo de genética. Para isso, foram apresentados aos entrevistados três opções de respostas: Muita Afinidade; Média Afinidade e Pouca Afinidade. Das respostas apresentadas, todos os professores consideraram ter entre média e muita afinidade com a matéria de genética.

Em seguida, analisando as metodologias que tais professores costumam utilizar, foram apresentadas algumas opções de atividades, abrindo espaço para que os profissionais expusessem outras estratégias que não constavam na lista e que já tinha sido utilizada em sua prática pedagógica (Tabela 2).

Tabela 2: Lista de dissertações selecionadas.

\begin{tabular}{c|cc}
\hline \hline Metodologia & $\mathrm{N}^{o}$ & $\%$ \\
\hline Aula expositiva & 6 & 100 \\
Recurso de mídia & 6 & 100 \\
Vídeo aula & 3 & 50 \\
Pesquisas de temas afins & 3 & 50 \\
Práticas em laboratório & 2 & 33 \\
Jogos didáticos & 2 & 33 \\
Outras & 1 & 17 \\
\hline \hline
\end{tabular}

A metodologia de aula expositiva com o uso de algum recurso de mídia (data show, retroprojetor, etc.), predominou, ou seja, $100 \%$ utilizam o método expositivo em suas as aulas de genética, apresentando poucas atividades que enfatizem outros tipos habilidades, além da percepção visual, como os jogos e práticas em laboratório.

Segundo Ribeiro e Ribeiro (2011), o predomínio no uso de aulas expositivas pela maioria dos professores, é algo que, infelizmente, resiste dentro do sistema educacional brasileiro. Ainda, conforme os autores, diante de turmas lotadas, os educadores encontram na metodologia de exposição verbalizada, uma espécie de "porto seguro", resistindo de várias formas em buscar inovação. Buscando aprofundar um pouco mais sobre o porquê da preferência por métodos mais tradicionais, como tam- bém pelo pouco uso de atividades concretas, os professores foram questionados acerca das dificuldades enfrentadas na preparação e na execução das aulas de genética, conforme apresentado na Tabela 3 .

Tabela 3: Lista de dissertações selecionadas.

\begin{tabular}{c|cc}
\hline \hline Dificuldades & $\mathrm{N}^{o}$ & $\%$ \\
\hline Interesse dos alunos & 4 & 67 \\
Falta de recurso & 3 & 50 \\
Ambiente Adequado & 2 & 33 \\
Probabilidades e estatística & 2 & 33 \\
Livro didático & 2 & 33 \\
Carga horária & 1 & 17 \\
\hline \hline
\end{tabular}

O item, "interesse dos alunos" mostrou-se como sendo a maior dificuldade dos professores no ensino do conteúdo de genética, corroborando com o resultado apresentado por (LIMA; VASCONCELOS, 2006), os quais afirmam que ultimamente têm sido frequentes os relatos de diversos educadores, por todo o Brasil, desde o ensino básico ao superior, sobre a falta de interesse e empenho dos alunos, em buscar conhecimento, na maioria das disciplinas.

No entanto, diante das respostas que foram apresentadas pelos professores, podemos verificar que esse dado majoritário da falta de interesse dos alunos, provavelmente representa o somatório de todos os outros fatores mencionados pelos entrevistados, justificando as dificuldades no processo de ensino num contexto geral, que são eles:

Falta de recursos - Os poucos subsídios financeiros, na maioria das vezes, limitam o professor na buscar por atividades que necessitam de infraestrutura e materiais mais elaborados. Assim, é necessário que sejam dadas condições estruturais no planejamento das aulas, visando à promoção do processo ensino - aprendizagem.

Ambiente adequado - Semelhantemente ao que descreve carvalho, Pereira e Ferreira (2009), a falta estrutura física, compromete o bem - estar físico dos alunos. Salas quentes, mal iluminadas e mobiliário degradado, dificultam a concentração dos estudantes, prejudicando o desenvolvimento cognitivo.

Matemática no conteúdo de genética - $\mathrm{O}$ conteúdo de genética possui um vocabulário extenso e, de maneira adicional, a presença dos conteúdos de estatística e probabilidade gera confusão entre aqueles que não possuem certa afinidade com cálculos (CID M.AND NETO, 2005). Portanto, uma alternativa seria a realização de parcerias entre professores de Biologia e Matemática, na busca por metodologias que trabalhem de maneira interdisciplinar os conteúdos. 
Livro didático - Apesar de ser escolhido pelos professores, mostra-se como uma reclamação recorrente quando se lista as dificuldades no ensino. De acordo com o PNLEM, é tarefa dos professores e da equipe pedagógica analisar as resenhas contidas no guia para escolher adequadamente os livros a serem utilizados no triênio. No entanto, é importante para os professores que não se detenham ao livro adotado pela escola na elaboração de suas aulas, é preciso buscar fontes complementares.

O Material didático é um fator importante para auxiliar a aprendizagem e estimular a vontade do aluno em aprender assuntos novos, pois o livro consiste na ferramenta mais utilizada em sala de aula, onde as informações serão transmitidas aos alunos. Dessa forma, necessita-se da verificação do instrumento didático, analisando se ele tem o papel de facilitador (TEMP 2011).

Em outra pergunta, buscou-se verificar as ferramentas avaliativas frequentemente utilizadas pelos entrevistados e, das várias metodologias apresentadas no questionário, à prova escrita foi apontada como sendo o método mais utilizado pelos professores $(100 \%)$.

Luckesi (2011) destaca que, por ser pontual, a prova escrita acaba por apenas classificar os alunos, no entanto, sem analisar a amplitude dos conhecimentos. Ainda segundo o autor, essa não é uma boa forma de se avaliar os alunos, pois é pouco inclusiva e, na maioria das vezes, funciona apenas como instrumento de repressão e autoritarismo. A avaliação deve ser proposital no sentido de ajudar a desvendar e traduzir os avanços e dificuldades apresentadas pelos alunos, na busca pela construção de um melhor resultado.

Porém, também foi destacada, pelos entrevistados, a realização de atividades práticas $(84 \%)$ e seminários (50\%), o que demonstra que os professores conhecem e tem se apropriado de outras ferramentas de avaliação mais abrangentes e integrativas.

Em última análise, quando questionados sobre o grau de satisfação em relação à forma como ministram suas aulas de genética, $50 \%$ dos professores afirmaram que estavam satisfeitos e 50\% disseram que não, justificando sua insatisfação em não conseguirem prender a atenção dos alunos ao conteúdo, que é reforçado pela deficiência de materiais que poderiam ser utilizados para tornar suas aulas mais atrativas.

Para Ramos (2002), a falta de sucesso dos alunos é uma das causas das preocupações dos professores que, acompanhadas de frustações, gera uma grande insatisfação. Outro problema que afeta diretamente a saúde do professores é a falta de material, ocasionando fases de grande estresse, por não terem como proporcionar aulas diferentes e de qualidade.

\subsection{Percepção dos alunos em relação às metodo- logias empregadas pelos professores}

Verificou-se junto aos alunos, o que estes entendiam por genética. Das respostas apresentadas, a maioria mostrou domínio apenas da conceituação geral, restrito às relações de transmissão de caracteres na espécie humana, como podem ser verificadas em algumas das respostas:

"É a ciência que estuda a hereditariedade, ou seja, as características que possuímos dos nossos familiares." (Entrevistado 03).

"É o assunto que trata sobre as nossas características, relacionado aos nossos pais." (Entrevistado 09).

"É a área da biologia que estuda a herança biológica, ou hereditariedade, que é a transmissão de características de pais para filhos, ao longo das gerações.” (Entrevistado 33).

Quanto ao entendimento do conteúdo de genética, cerca de $17 \%$ dos estudantes citaram que não entenderam nenhum conteúdo, deixaram em branco e/ou que não lembravam. Porém, também verificou-se que uma pequena parcela desses estudantes não conseguiram conceituar ou associar o que é estabelecido pelo conteúdo de genética, como pôde ser observado em outras respostas apresentadas por alguns deles:

"Pouca coisa, pois não me recordo muito." (Entrevistado 07).

"Nada." (Entrevistado 20).

"Nada, porque é muito difícil." (Entrevistado $30)$.

"Nada, na verdade um pouco." (Entrevistado $45)$.

Torna-se evidente que uma parcela desses alunos está concluindo do Ensino Médio, sem ao menos compreender o básico proposto pelas leis que regem a hereditariedade nos seres vivos. Além disso, as informações supracitadas sinalizam que providências precisam ser tomadas no sentido de minimizar esse tipo de insucesso. Os PCNs (2008) estabelecem que é dever dos professores e das escolas assumirem a tarefa de viabilizar que os alunos saiam do Ensino Médio compreendendo os principais fundamentos científico-tecnológicos e sendo 
A GENÉTICA EM SALA DE AULA: UMA ANÁLISE DAS PERCEPÇÕES E METODOLOGIAS EMPREGADAS POR PROFESSORES DAS ESCOLAS PÚBLICAS ESTADUAIS DE JAGUARIBE CEARÁ

capazes de relacionar a teoria com prática. Nesses fundamentos, incluem-se os conhecimentos em genética.

Assim, mediante a ideia de que a genética está presente no dia-dia da humanidade e que os avanços genéticos e tecnológicos vêm proporcionando aos cientistas um entendimento mais abrangente das modificações genéticas e de suas influências na predisposição ou no desenvolvimento de muitas enfermidades (FLORIASANTOS; NASCIMENTO, 2006), são graves as constatações feitas pelo presente trabalho, acerca das percepções que os alunos têm desse conhecimento científico.

De maneira adicional, buscou-se obter, dos alunos, os resultados acerca do que na matéria genética lhes chamou mais a atenção, na primeira vez em que foi apresentada em sala de aula: $37 \%$ dos entrevistados responderam que o assunto de conhecimentos básicos em genética foi o que chamou mais atenção, como pode ser observado na Figura 1 .

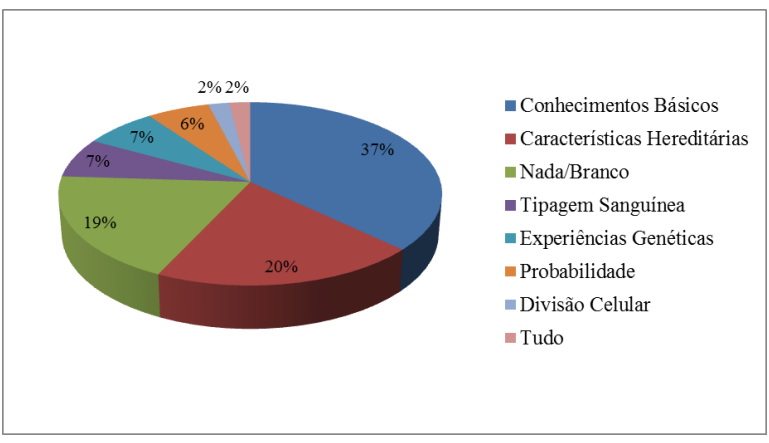

Figura 1: Análise da pergunta sobre o que chamou mais atenção na disciplina de genética, para os alunos.

Na tabulação dada, em $37 \%$ das respostas, foram caracterizados, como sendo "Conhecimentos básicos", aqueles que colocaram conceitos básicos estabelecidos dentro do conhecimento genético (genótipo, fenótipo, genes, alelos, etc.), já com relação ao que esse estudo atribuiu como "Características Hereditárias", 20\% das respostas apresentaram dados no sentido de associaram o que foi exposto em sala a situações cotidianas dos alunos como, por exemplo, a transmissão de características físicas de pais para filhos.

No geral, pode-se afirmar que a maioria dos entrevistados se deteve aos significados de termos e expressões dentro da genética (Conhecimentos básicos), bem como o que de alguma forma eles associaram ao sua vivência familiar e parental, algo que poderia ser utilizado para ampliar o conhecimento acerca da temática.

Segundo Pelizzari et al. (2002), o conhecimento prévio dos alunos é a ponte para a construção de um novo conhecimento, assim como a soma de sua competência cognitiva e de seus conhecimentos prévios marcará o nível de desenvolvimento dos alunos.

Foram analisadas as percepções dos alunos sobre as metodologias usadas nas aulas pelos professores da disciplina e dos alunos, dos quais $61 \%$ confirmam a predominância das aulas expositivas, assim como apresentado na tabela 04, corroborando, em parte, o que foi informado pelos professores.

É importante enfatizar que a aula expositiva, mais comum no cotidiano escolar, conta com a desvantagem da passividade dos alunos, o que gera a dispersão e pequena retenção de informações, o que mostra a necessidade de se encontrar outras formas de trabalho que permitam uma melhor qualidade na aprendizagem (KRASILCHIK, 2008).

Tabela 4: Lista de dissertações selecionadas.

\begin{tabular}{c|cc}
\hline \hline Metodologia & $\mathrm{N}^{o}$ & $\%$ \\
\hline Aula expositiva & 37 & 61 \\
Recurso de mídia & 37 & 61 \\
Vídeo aula & 14 & 50 \\
\hline \hline
\end{tabular}

Apesar disso, para Krasilchik (2008), o ensino informativo, representado pela aula expositiva, pode, alternativamente, ser transformado em uma metodologia produtiva, desde que sejam introduzidas ações de discussões dialogadas, motivando o aluno e auxiliando-o na exposição de suas ideias, ao invés de limitá-lo a apenas ouvir o professor.

Em continuação ao estudo, foram identificadas as dificuldades apresentadas, pelos alunos, em entender o conteúdo de genética (Tabela 5 ).

Tabela 5: Lista de dissertações selecionadas.

\begin{tabular}{c|cc}
\hline \hline Dificuldades & $\mathrm{N}^{\circ}$ & $\%$ \\
\hline Compreensão dos termos do Livro & 15 & 28 \\
Uso da Matemática (Probabilidade e Estatística) & 15 & 28 \\
Didática do Professor & 8 & 15 \\
Poucas Atividades Diferentes & 8 & 15 \\
Falta de Livros & 3 & 6 \\
Nada & 2 & 4 \\
Heredograma & 2 & 4 \\
Sem Responder & 2 & 4 \\
Estrutura da Sala de Aula & 1 & 2 \\
\hline \hline
\end{tabular}

Do total de alunos entrevistados, 28\% afirmaram sentir dificuldades na compreensão dos termos que o 
livro utiliza, pois a disciplina possui uma linguagem muito técnica.

Moreira e Silva (2001) apontam para o fato de que esses conceitos não fazem parte do cotidiano do aluno, elevando ainda mais a dificuldade em compreenderem termos tão abstratos e complexos.

Dificuldades em Matemática também representaram $28 \%$ dos resultados apontados. De maneira similar, em estudo desenvolvido por Barni (2010), a maioria dos estudantes analisados, da escola estadual, no município de Gaspar, Santa Catarina, traz a Matemática como uma das dificuldades na compreensão da genética. Segundo o autor, os estudantes mencionaram que sempre gostaram de Biologia e que estavam ansiosos para os conteúdos de Genética, porém não imaginavam que teriam de lidar com a Matemática. Assim, o autor relaciona o descontentamento com a matéria genética aos problemas de domínio em outras áreas do conhecimento que são auxiliares à disciplina.

Outros dois fatores importantes, apontados pelos estudantes, foram relacionados à didática do educador e ao uso de poucas atividades diferentes das apresentadas no quadro, ambas com $15 \%$. É importante que os conceitos de genética sejam bem compreendidos, contudo, para que isso ocorra, o educador necessita buscar novas metodologias com o intuito de diferenciar suas aulas, por meio de atividades diversificadas e/ou concretas e que causem entusiasmo, estimulando os estudantes na construção do saber (TEMP, 2011).

Por fim, de maneira similar ao que foi indagado aos professores, aferiu-se o grau de satisfação dos alunos em relação às aulas de genética, solicitando, em seguida, que dessem sugestões sobre o que, na concepção deles, melhoraria a aprendizagem desse conteúdo escolar. Acerca disso, cerca de $13 \%$ responderam que estavam totalmente satisfeitos com as aulas de Biologia, $26 \%$ afirmam estar insatisfeitos e $61 \%$ responderam que estavam satisfeitos, o que visualizamos no Figura 2

Já em relação às sugestões de como seria uma boa aula de genética, $43 \%$ dos alunos afirmaram que o ideal seria a utilização de aulas práticas, e $22 \%$ dos entrevistados afirmaram que os professores precisam tornar suas aulas mais explicativas, diversificando a metodologia, tornando-as mais atrativas. Cerca de $17 \%$ dos alunos não mudariam nada e, para $9 \%$ dos entrevistados, a aula ideal seria com a utilização de mais exemplos em sala. (Figura 3).

Para 7\%, a utilização de vídeo-aula traria uma melhoria nas aulas de genética e para outros $2 \%$ o conteúdo de genética deveria ser excluído do conteúdo programática do disciplina de Biologia a ser visto no ensino médio.

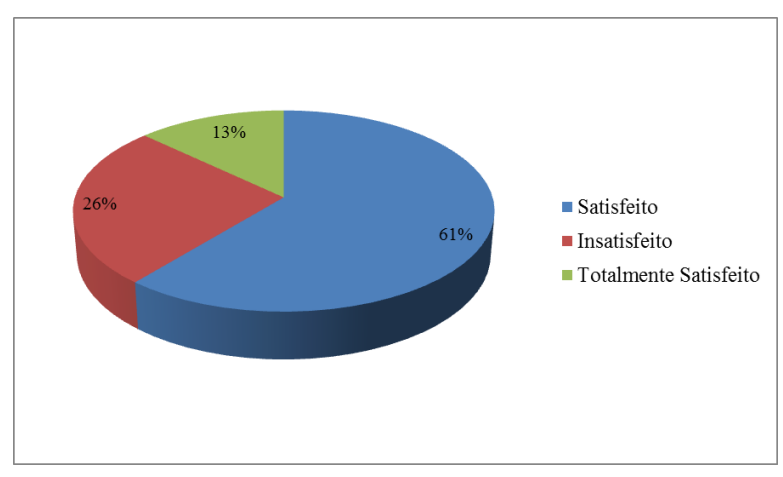

Figura 2: Análise de satisfação dos alunos da disciplina de genética das escolas estaduais do município de Jaguaribe, Ceará, Brasil.

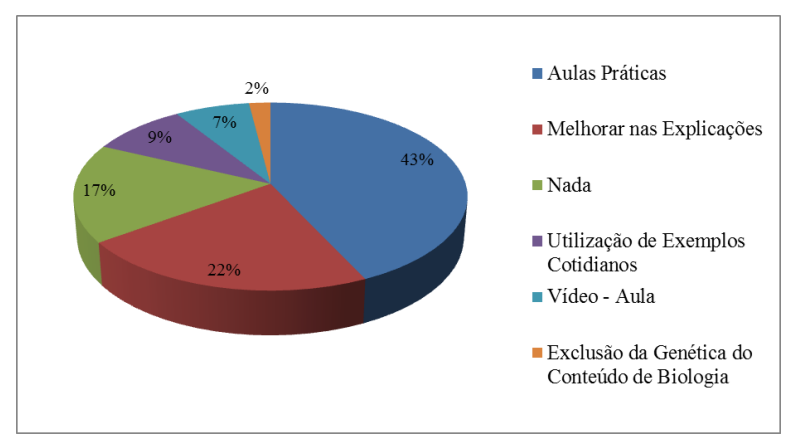

Figura 3: Análise de como seria a aula ideal, na visão dos alunos e o que eles mudariam para melhorar o aprendizado. 
A GENÉTICA EM SALA DE AULA: UMA ANÁLISE DAS PERCEPÇÕES E METODOLOGIAS EMPREGADAS POR PROFESSORES DAS ESCOLAS PÚBLICAS ESTADUAIS DE JAGUARIBE CEARÁ

Segundo Pedroso (2009), as atividades lúdicas, em especial o jogo didático, é a melhor maneira de aprimorar as relações entre professor/aluno. Claramente, as atividades lúdicas proporcionam, ao indivíduo, um ambiente agradável, motivador e prazeroso. Outra importante vantagem, no uso de atividades lúdicas, é a tendência em motivar o aluno a participar espontaneamente na aula.

O trabalho de Vilhena et al. (2010), mostra como preparar modelos didáticos de baixo custo para serem utilizados como referenciais nas aulas de genética, utilizando materiais didáticos em sala de aula, que auxiliam o professor e ajuda na compreensão dos alunos, como exemplo os jogos. Assim, é preciso que os professores deem maior ênfase no desenvolvimento de atividades que busquem reduzir as distâncias entre o conhecimento científico e a realidade cotidiana dos alunos. No entanto, isso somente será possível através de metodologias acessíveis e bem planejadas no propósito de aprendizagem.

\section{CONSIDERAÇÕES FINAIS}

Diante dos resultados encontrados na pesquisa, foi possível perceber que o ensino de genética nas escolas estaduais de Jaguaribe, ainda está voltado principalmente às aulas expositivas, que prevaleceram em $100 \%$ das respostas dadas pelos professores. Esse tipo de metodologia, utilizada de forma predominante, possui uma série de desvantagens, como a passividade dos alunos no momento da explicação, podendo gerar dispersão e pouca assimilação de conhecimento.

De maneira adicional, esse estudo demonstra que os alunos possuem dificuldade em compreender o conteúdo de genética, devido a déficits de formação de base em outras disciplinas, principalmente a Matemática, que é bastante utilizada dentro dos cruzamentos e cálculos de probabilidade. Diante disso, a visualização e consequentemente concretização do conhecimento, apenas através da exposição oral do professor, é prejudicada.

Assim, é preciso que os professores deem maior ênfase no desenvolvimento de atividades que busquem reduzir as carências de formação de base em séries anteriores, por meio de atividades de reforço, que visem sanar as deficiências e promovam uma maior participação dos alunos na construção do conhecimento, por meio do uso de recursos audiovisuais, jogos e atividades práticas, que podem ser as melhores alternativas na construção desse ambiente mais favorável à aprendizagem de conceitos, na medida em que o aluno é levado a refletir, fazer previsões e inter-relacionar objetos e eventos.
Por fim, é importante destacar que, além das mudanças metodológicas empregadas pelos profissionais, é interessante que o poder público possibilite um melhor aparelhamento de ambientes para a execução das atividades concretas, como a estruturação de laboratórios e equipamentos de multimídia, possibilitando a articulação dos conteúdos de genética com o que é planejado pelo professor.

\section{REFERÊNCIAS}

ALBANO, L. M. J. Importância da genética no serviço público: relato da extinção de um setor de genética no município de são paulo. Revista Panam Salud Publica, v. 7, n. 1, p. 29-34, 2000.

BARDINI, L. Análise de conteúdo. : Lisboa, 2009.

BARNI, G. A importância e o sentido de estudar genética para estudantes do terceiro ano do ensino médio em uma escola da rede estadual de ensino em Gaspar (Sc). Dissertação (Mestrado) - Universidade Regional de Blumenau, 2010.

BRASIL. Parâmetros curriculares Nacionais Ensino Médio: PcNEM. ciências da Natureza, Matemática e suas tecnologias. Brasília, 1999.

CANAL, R. R.; BASTOS, F. The approach of contempory themes in teching of biology: Analysis of a pedagogic experience. Enseñanza de las ciencias, v. 6, p. 33-34, 2001.

CARVALHO, M.; PEREIRA, V. c.; FERREIRA, S. P. A. A (des)motivação da aprendizagem de alunos de escola pública do ensino fundamental i: Quais fatores envolvidos? In: Projeto Saber Travessias. Recife: , 2009. v. 3.

CID M.AND NETO, A. J. Dificuldades de aprendizagem e conhecimento pedagógico do conteúdo: O caso da genética. Enseñanza De Las ciências, v. 1, n. extra, p. 1-5, 2005.

COSTA, M. V. Estudos culturais em educação: mídia, arquitetura, brinquedo, biologia, literatura, cinema. Revista Brasileira de Educação, v. 1, n. 17, p. 43-46, 2000.

FLORIA-SANTOS, M.; NASCIMENTO, L. c. Perspectivas históricas do projeto genoma e a evolução da enfermagem. Revista Brasileira de Enfermagem, v. 59, n. 3, p. 358-361, 2006.

GALIAZZI, M. c.; GONCALVES, F. P. A natureza pedagógica da experimentação: Uma pesquisa na 
A GENÉTICA EM SALA DE AULA: UMA ANÁLISE DAS PERCEPÇÕES E METODOLOGIAS EMPREGADAS POR PROFESSORES DAS ESCOLAS PÚBLICAS ESTADUAIS DE JAGUARIBE CEARÁ

licenciatura em química. Química Nova, v. 27, n. 2, p. $\quad$ SNUSTAD, D. P.; SIMMONS, M. J. Fundamentos da 326-331, 2004.

Genética. : Guanabara Koogan, 2012.

KLUG, W.; CUMMINGS, M. R.; SPENCER, c. A.; PALLADINO, M. A. conceitos de Genética. 9. ed. : Artmed, 2010.

KRASILCHIK, M. Prática de ensino de Biologia. 4. ed. : EDUSP, 2008.

LIMA, K. E. c.; VASCONCELOS, S. D. Análise da metodologia de ensino de ciências nas escolas da rede municipal de recife. Ensaio: Avaliação das Políticas Públicas em Educação, v. 14, n. 52, p. 397-412, 2006.

LIMA, M. F. F.; SOARES, Z. M. J.; MARTINS, L. S. S.; ANJOS, A. M. c. L. A compreensão das leis de mendel por alunos de biologia na educação básica e na licenciatura. Ensaio: Pesquisa em Educação em ciência., v. 8, n. 1, p. 1-21, 2006.

LUCKESI, c. c. Avaliação da aprendizagem escolar: estudos e proposições. : Ed. cortez, 2011.

MOREIRA, M. c. A.; SILVA, E. P. concepções prévias. uma revisão de alguns resultados sobre genética e evolução. In: Encontro Regional de Ensino de Biologia. 2001. v. 1, p. 490-504.

PEDROSO, c. V. Jogos didáticos no ensino de biologia: Uma proposta metodológica baseada em módulo didático. In: IX congresso Nacional de Educação-e III Encontro Sul Brasileiro de Psicopedagogia. Paraná: , 2009.

PELIZZARI, A.; KRIEGL, M. L.; BARON, M. P.; FINCK, N. T. L.; DOROCINSKI, S. I. Teoria da aprendizagem significativa segundo ausubel. Revista $P E c$, v. 2, n. 1, p. 37-42, 2002.

RAMOS, S. I. V. Satisfação/insatisfação profissional em professores de educação física do quadro de nomeação definitiva de coimbra: um estudo descritivo. Tese (Doutorado) — coimbra, 2002.

RIBEIRO, V. M. B.; RIBEIRO, A. M. B. A aula e a sala de aula: um espaço-tempo de produção de conhecimento. Revista do colégio Brasileiro de cirurgiões., v. 38, n. 1, p. 71-76, 2011.

SARDINHA, R.; FONSECA, M.; GOLDBACH, T. $\mathrm{O}$ que dizem os trabalhos dos anais dos encontros nacionais de pesquisa em ensino de ciências sobre ensino de genética. In: VII ENPEc, Encontro Nacional de Pesquisa em Educação em ciências. Florianópolis: , 2009. 